\title{
TRABALHO E DESIGUALDADE
}

O Centro de Estudos das Relações do Trabalho e Desigualdades (CEERT) é uma organização não-governamental, sem fins lucrativos, que vem se dedicando, desde 1990, à pesquisa e intervenção na área de relações raciais e de gênero, à promoção da igualdade de oportunidades e tratamento, e ao exercício da cidadania.

Desde 1993 o CEERT atua na área da Educação através do projeto Educação para a Cidadania, que teve apoio inicial da Fundação Ford e posterior da Fundação LéviStrauss. O principal objetivo dessa ação tem sido capacitar e sensibilizar educadores sobre a importância de tratar da questão da pluralidade étnica e cultural no meio escolar, a fim de garantir que esse espaço seja isento de toda e qualquer forma de discriminação.

As realizações até o momento compreendem cursos, seminários, produção de textos e atividades interculturais, abordando os seguintes temas: repetência e evasão escolar; o negro na História e no ensino de História do Brasil; racismo: preconceito e estereótipos; o conteúdo dos livros didáticos; relações interétnicas/raciais no meio escolar.

O programa desenvolvido tem cumprido um papel importante na sensibilização para essa temática, mas já não é o bastante para atender às necessidades dos contextos mobilizados. Em nossa experiência destes últimos anos, tornou-se evidente a lacuna existente no universo educacional no que se

\section{A AUTORA}

Maria Aparecida Silva Bento

Professora Doutora, coordenadora do Centro de Estudos das Relações de Trabalho e Desigualdades (CEERT).E-mail: sibento@uol.com.br refere a uma metodologia que permita a transformação das relações marcadas por desigualdades de tratamento e de oportunidades no cotidiano escolar.

O CEERT privilegia uma abordagem psicossocial na área de relações interétnicas, o que explica a sua escolha de trabalhar, sempre que possível, com grupos em oficinas. Através de métodos expressivos, os participantes podem ultrapassar o plano intelectual das discussões sobre os fenômenos sociais, podendo entrar em contato também com a realidade subjetiva que influencia a sua ação, e se expressar de maneira espontânea.

\section{ATIVIDADES EM CURSO}

\section{PROJETO CAPACITAÇÃO SINDICAL}

\section{Objetivos:}

- Programa de formação - Investimentos na criação de massa crítica no campo sindical para a elaboração de políticas sindicais antidiscriminatórias; ampliação geográfica do programa de formação, produção de materiais educacionais, lançamento de uma Campanha nacional pela implementação da Convenção 111 da Organização Internacional do Trabalho (OIT).

- Programa de pesquisa - Pesquisar o perfil dos sindicalistas mobilizados a freqüentar os cursos; subsidiar o programa de formação com pesquisas bibliográficas; elaborar metodologia para intervenção junto a diferentes categorias do movimento sindical.

Metodologia: cursos, oficinas e seminários.

Resultados: Reclamação formal à OIT, denunciando o descumprimento da Convenção 
111; criação do GTEDEO (Grupo de Trabalho para a Eliminação da Discriminação - Fundação Ford/Fundação MacArthur).

\section{PROJETO EDUCAÇÃO PARA A CIDADANIA}

Objetivo: sensibilizar e capacitar educadores no tratamento da diversidade étnica/ racial e de gênero em meio escolar.

Metodologia: cursos, oficinas e seminários.

Resultados: ampla discussão com professores sobre o conteúdo dos livros didáticos, enfocando conceitos como racismo, preconceito e estereótipos, e sobre a imagem do negro veiculada através do ensino oficial da disciplina História; sensibilização de educadores e alunos sobre as relações interétnicas no espaço escolar; produção literária sobre a temática raça e educação.

Apoio: Fundação Lévi-Straus.

\section{PROJETO A INTERAÇÃO \\ PLURIÉTNICA NO MEIO ESCOLAR}

Objetivo: capacitação e assessoramento político-cultural, no campo da educação, com vistas a contribuir no detalhamento e na articulação da proposta de transversalidade dos Parâmetros Curriculares Nacionais, nas ações direcionadas à pluralidade étnico-cultural no meio escolar.

\section{PROJETO OPORTUNIDADES IGUAIS PARA TODOS}

\section{Objetivos:}

- Análise da composição e da trajetória profissional dos funcionários públicos da Prefeitura Municipal de Belo Horizonte (MG) para identificação das desigualdades de gênero e de raça. Sensibilização dos profissionais da área de recursos humanos e chefias das Regionais no tratamento da diversidade com vistas à obtenção de eqüidade em matéria de emprego. Produção de material de divulgação (folder e cartaz).

- Introdução do quesito cor nos cadastros do sistema de informação sobre saúde.

- Sensibilizar professores e profissionais da educação para a dimensão e a importância do dado da cor/raça no desenvolvimento escolar das crianças negras, além de propor uma reflexão aprofundada da intersecção relações raciais/educação.

Metodologia: análise de discurso com abordagem psicanalítica (oficinas/entrevistas).

Resultados: treinamento de cerca de 500 professores da rede municipal de ensino para o tratamento adequado da temática racial na sala de aula; introdução do quesito cor no sistema municipal de informação sobre saúde e conseqüente treinamento de 300 profissionais da área, os quais atuarão como monitores na coleta do quesito; realização de uma pesquisa sobre a representação de negros e mulheres no imaginário dos profissionais de recursos humanos e chefias intermediárias, que resultou em importantes subsídios para a adoção de uma política de promoção da igualdade de raça e gênero no funcionalismo.

Apoio: Prefeitura Municipal de Belo Horizonte.

\section{PROJETO DIREITO E RELAÇÕES RACIAIS}

Objetivos: pesquisar a jurisprudência e estudos sobre a gênese, aplicabilidade e eficácia da legislação antidiscriminatória existente; oferecer subsídios e formação para operadores do Direito e demais interessados no aspecto jurí- 
dico do fenômeno discriminatório, elaboração de um Anteprojeto de Lei Civil de Promoção da Igualdade

Metodologia: seminários, publicações e

Resumo: A autora faz a apresentação do Centro de Estudos das Relações do Trabalho e Desigualdades (CEERT), seus princípios norteadores e ações desenvolvidas. Ressalta a experiência da instituição nestes últimos anos evidenciando a inexistência, no universo educacional, de uma metodologia que permita a transformação das relações marcadas por desigualdades de tratamento e de oportunidades no cotidiano escolar. Passa, em seguida, a uma descrição esquemática dos projetos da entidade, descrevendo os objetivos, metodologias e resultados de cada um.

Palavras-chave: CEERT, etnia, igualdade, racismo, negros, mulheres palestras.

Resultados: em curso.

Apoio: Comunidade Européia e Ministério da Justiça.

Abstract: The author presents the "Centro de Estudos das Relações do Trabalho e Desigualdades" (CEERT, or Center for the Study of Work Relations and Inequalities), its basic principles and actions. The article emphasizes the institution's experience in the past years, making evident the absence, in the educational universe, of a methodology that allows for the transformations of relations marked by inequality in treatment and opportunities in the day-to-day in school. The article goes on to making a schematic description of the entity's projects, describing the objectives, methodologies and results reached.

Key words: CEERT, ethnic group, equality, racism, blacks, women 